DOI: 10.33727/JRISS.2021.2.14:132-139

\title{
Mechanical design of corrugated packaging box
}

\author{
Florin Ionut Boaca ${ }^{1}$, Sorin Cananau ${ }^{2}$, Delia Prisecaru ${ }^{2}$, Marilena Stoica ${ }^{2}$, Lucian \\ Cucu $^{2}$ \\ ${ }^{1}$ Industrial Engineering Politehnica University of Bucharest, Romania \\ ${ }^{2}$ Machine Elements and Tribology Department, Politehnica University of Bucharest, Romania \\ E-mail: florin_ionut.boaca@stud.mec.upb.ro; sorin.cananau@upb.ro
}

\begin{abstract}
Without packaging, it would be very difficult to distribute consumer goods. The packaging protects the merchandise during shipment, informs the user about the product, extends the life of the product, and last but not least, it helps the economy and the recycling process, especially with the latest trend on being environmentally friendly. A packaging box should confer mechanical protection when manipulating the product, but also should be economically feasible when it comes to production costs. The packaging material that meets the above criteria is cellulose. "Packages made from corrugated cardboard are products made from renewable raw materials, which can be optimally integrated into production cycles"[1]. Design packaging takes into account factors like manipulation, shipping, distribution, and product marketing by using graphics and information printed on the package. As a result of this, packaging designers are looking for solutions that make the packaging life cycle optimal and feasible when taking into account factors like mechanical strength, chemical, climatic and biologic.
\end{abstract}

Keywords: packaging box, corrugated cardboard, mechanical strength

\section{Introduction}

Without corrugated cardboard, the world of packaging would find it difficult to distribute, store and protect the product until it reaches the functionality for which it was designed. To use corrugated cardboard and design packaging from this material it is very important to know its mechanical properties.

Today's packaging, in addition to its main functions, protection and preservation, has the ability to be a means of communication between the manufacturer and the final consumer about the packaged product. Through communication, the packaging justifies the quality of the product and informs the customer to a higher level.

This aspect took an important direction in the marketing of the products, later becoming the main seller. If we analyze the packaging by its main function and its role in most industries we can say that packaging is the factor of protection or isolation of a product or a group of products with the aim of transporting, storing or enhancing them for commercial or aesthetic purposes.

So from a main function, namely the protection function, it has come over time to receive increased attention in terms of functionality, aesthetics and especially the way of recycling when it has fully fulfilled all its functions, bothmain as well as secondary. Packaging made of cellulosic materials are special packaging, I say special because they are different in their properties, these materials can create a clean ecosystem worldwide. Diana Twede said in the book Cartons, Crates and Corrugated 
Board "that they are transient, like us, and their nature determines the unique properties of the packaging made from them" [2].

If we examine what Diana Twede said we can conclude that paper and cardboard are part of the human economy with the possibility of reuse and the ability to cause a cycle with an imprint on the ecology and safety of the packaged product. So, if we stop for a moment and analyze the above, we can conclude that cellulose materials can be recycled and reused at the maximum possible level.

„This century has witnessed remarkable achievements in green technology in the field of materials science through the development of high-performance materials made from natural resources is increasing worldwide. Plant fibres are a kind of renewable resources, which have been renewed by nature and human ingenuity for thousands of years”[3]. „In addition, cellulose possesses many attractive properties, such as tremendous reversibility, complete biodegradability, excellent biocompatibility, high mechanical property and structural designability"[4].

\section{Corrugated cardboard}

We saw above that, due to its protective properties, low production price and degree of ecology, corrugated cardboard is one of the most popular materials used. Given these extraordinary properties for the packaging industry, corrugated cardboard has been adopted for many types of packaging, replacing metal or wooden packaging over the years, thus contributing to the economic optimization of products by reducing the weight of transport (in the case of wooden packaging or metal a large part of the transported load, is represented by the weight of the packaging) and the efficiency of technological processes of packaging manufacturing (this material does not require a large advance of processing compared to wooden or metal packaging.) In the case of corrugated board the mechanical strength is influenced by the corrugated profile, more precisely the profile confers a rigidity, but especially the stacking strength for corrugated packaging, the most interesting thing is the empty space, resulting from the sinusoidal shape of the corrugation and the outer walls, this air gap allows the packaging to be insulated.

\subsection{Classification of the type of corrugated board}

Depending on the number of layers of paper, corrugated cardboard differs as follows: type II, III, V, VII, known technologically and as: $\mathrm{CO} 2, \mathrm{CO} 3, \mathrm{CO} 5, \mathrm{CO} 7$.

- type II or $\mathrm{CO} 2$ - consists of a cover and a core paper, this assembly is made by gluing, gluing is done between the top of the corrugations and the cover,

- type III or CO3 - is made of a corrugated layer, and in turn is glued between two smooth layers;

- type V or CO5 - this type is made of two wavy layers and three smooth layers;

- type VII or CO7 is made of three corrugated layers and four smooth layers.

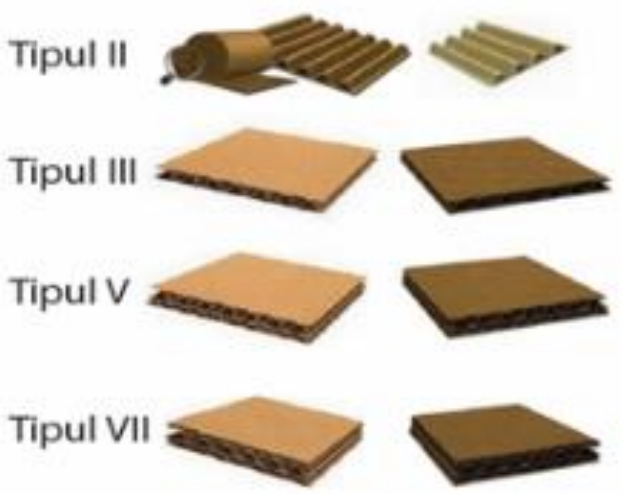

Figure 1. Types of cardboard [5]. 
Another classification criterion is the size of the corrugations, defined by the height (h) and pitch (p) of the corrugation in the core paper.

"Usually, the number of layers in a corrugated board depends on the packaging requirements. In an outer wall, meaning only one side of the corrugated cardboard structure, there are two layers: the protective sheet and the corrugated paper. The corrugated sandwich structure consists of three layers: two walls and the corrugated (core)" [6]. About $80 \%$ of corrugated board is manufactured as a single wall board. Double and triple wall corrugated boards consist of five and seven layers, respectively (Fig. 1.). The corrugated board is manufactured in several standard flute profiles. Flute profiles are characterized by the letters A, B, C, E or F.

\subsection{Corrugated packaging}

Cardboard boxes have a wide range of uses, being used by manufacturers and logistics companies around the world for packaging, transport, protection and storage of products. Yi Yi said in the Life cycle assessment of delivery packages in China in 2016 -"Roughly $70 \%$ of corrugated boxes are made of 2-layer paperboards and 30\% are made of 1-layer" [7].

The cardboard boxes aim to transport the product in optimal conditions, offering useful information for their identification and marketing. They are developed in the department, product design in such a way that they can be stored and arranged easily and efficiently in open or closed spaces. Life without packaging would be extremely complicated for the consumer in many ways, often the consumer treats the packaging with indifference, all the more so, the packaging is thrown away at random by many users, and this is not to be neglected at all. ecology. of the planet. In the last decade, the growth of online shopping has grown so much that packaging has become an important and decisive factor in graphics and form, but also for easy identification of the product throughout the handling, storage and distribution, from the manufacturer, department logistics until its use.

\subsection{The advantages of corrugated boxes packages}

Corrugated boxes have replaced wooden and tin containers due to the many advantages for the safe transport of goods. The main advantages are:

- Cellular structure with high compressive strength, shock resistance;

- It can be stored in a folded state when not in use, thus saving storage space;

- It can be printed attractively, thus developing sales and information strategies;

- $\quad$ Easy to make;

- Maximum availability;

- Accelerated production;

- They are reusable;

- Optimal on the export market

\subsection{Disadvantages of using corrugated boxes packages}

Corrugated cardboard is very sensitive to moisture. This humidity of the environment influences the mechanical properties of the corrugated cardboard, so the packaging loses its main function and the product becomes vulnerable and prone to damage.

\section{The main functions of corrugated board}

\subsection{Protection}

Protecting a product is the main reason why we use a package, of course there are other factors as important as information for good management or much faster identification of products, stacking in warehouses or means of transport, but the protection factor is the first important factor for a product to be marketed. So protection is damage prevention and optimization throughout the distribution process. The protection cycle of a product is as follows: manufacturing operations, packaging, storage and handling in warehouses, transport to the trader, distributor or store for sale, purchase and end use. 
During these stages, damage may occur at each of the above stages, but in most cases, damage to the product occurs as a result of storage in accordance with current standards and especially during transport. This damage to non-compliant storage is caused by environmental factors such as humidity.

\subsection{Mechanical comportment to impact}

During transport or storage, the packaging is subjected to shocks and compression.

Bivainis said ,that the properties of corrugated board are determined by the purpose and size of the package, the thickness, the layers of constituent paper, the number of layers and the type of profile used". [8]
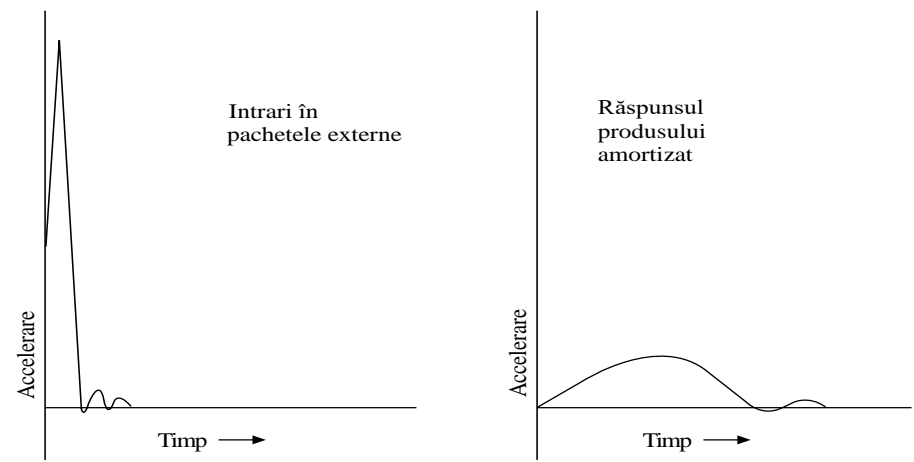

Figure. 2. Shock - Anne Emblem and Henry Emblem, Packaging Technology, Fundamentals, Materials and Process, Woodhead Publishing, 2012. [9].

\subsection{Mechanical comportment to vibrations}

Vibrations have a complex harmful effect on packaging, by the presence of these vibrations during transport, the packaging performs its function of dampening their degree making it possible to distribute products safely. Vibrations during road transport are the most dangerous for the packaged product. The displaced distance is the amplitude, and the number of oscillations per second is the frequency measured in hertz $(\mathrm{Hz})$. The sandwich structure of corrugated cardboard is able to absorb vibrations and dampen their effect. The corrugated cardboard structure is among the most ideal materials for packaging products. Mechanical vibrations and shocks are dynamic phenomena, ie the intensity varies over time. To determine these dynamic phenomena it is necessary to use special equipment.

Standardized tables (eg trucks) are used to simulate vibrations that occur during transport. "Vibration tests could be random or sinusoidal vibrations" [9] (Shock - Anne Emblem and Henry Emblem, Packaging Technology, Fundamentals, Materials and Process, Woodhead Publishing, 2012).

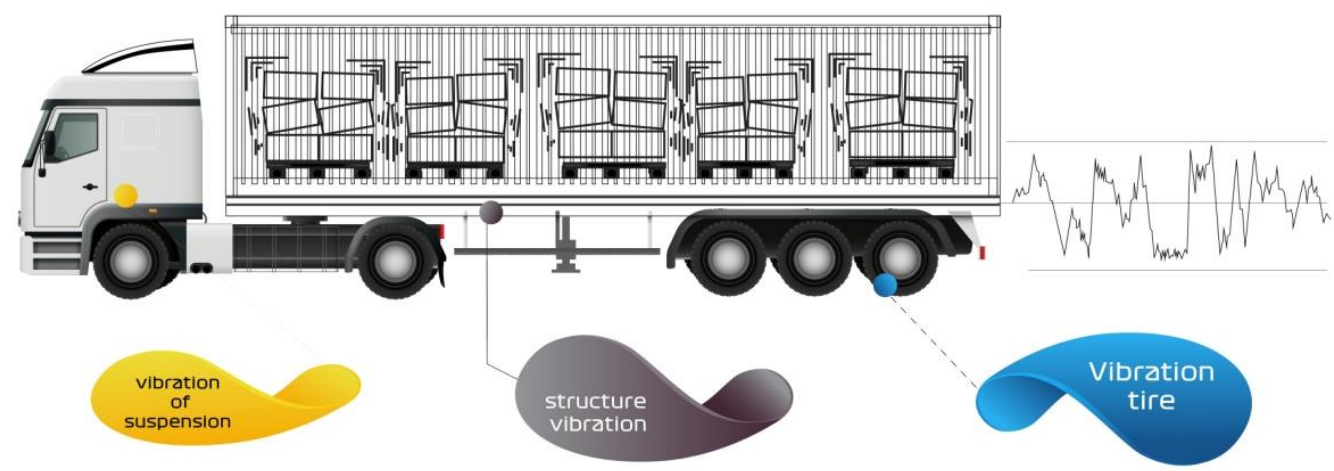

Figure.3. Vibrations during road transport.Compression 
The compressive strength of the packaging is a very important factor in the design stage. The challenge for the designer is to understand the compressive forces and to design packaging with appropriate specifications to limit any damage to the packaged product. If in warehouses the packages face compression in stationary regime, during transport these packages are subjected to a dynamic compression, this aspect is a delicate one, because the type of corrugated cardboard used in the production of packaging must fulfill functions of resistance to vibrating stresses.

For a correct calculation, factors such as: handling factor, force on the box depending on the transport time, even the packaged content (product) cause vibrations are taken into account, which leads to the use of the safety coefficient when stacking. This coefficient is the sum of the partial coefficients.

\subsection{Mechanical design}

In Figure. 4 is presented the stress-strain curve which enclosed three aspects, namely [10]:

a) Elastic deformation;

b) Compression reaching the crushing threshold when this point is exceeded;

c) Folding.

Consequently, the strength of a corrugated box can be determined as well as the resistance of the edges to compression.

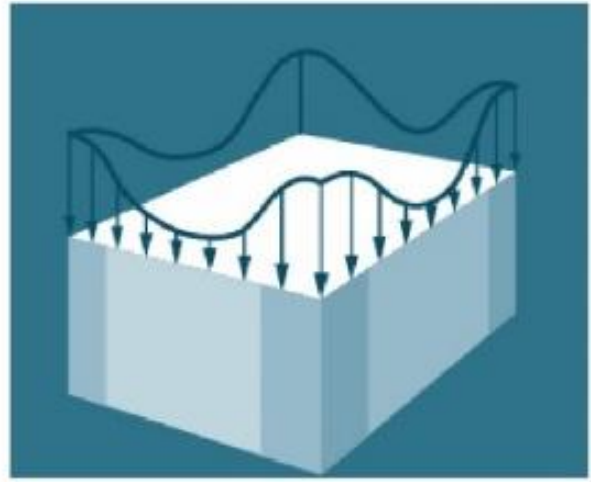

$\boldsymbol{A}$

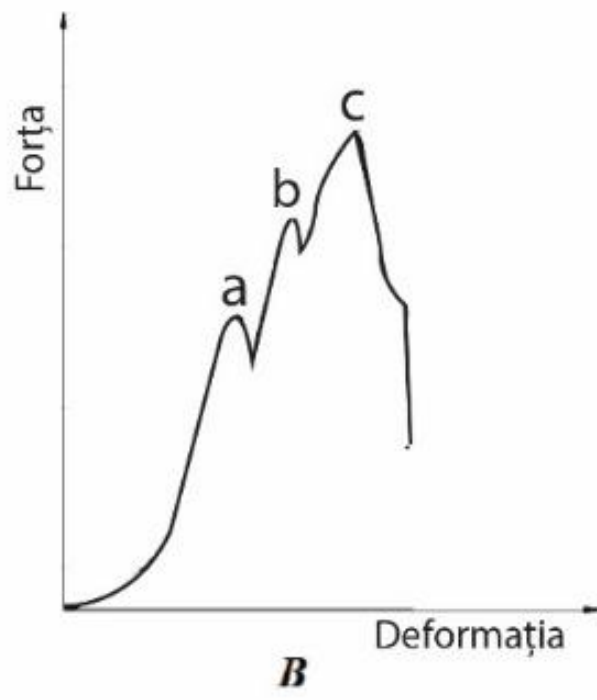

B

Figure 4. Distribution of loads at the compression request in the bottom-up direction of corrugated boxes $(A)$ and the typical shape of the stress-strain curve (B) $[11,12]$

\subsection{Model of mechanical design}

In this paper we will compute a test for mechanical strength of a box packaging model. The corrugated cardboard model is presented in Fig.1-type III and the model of a box is presented in Figure 5. 


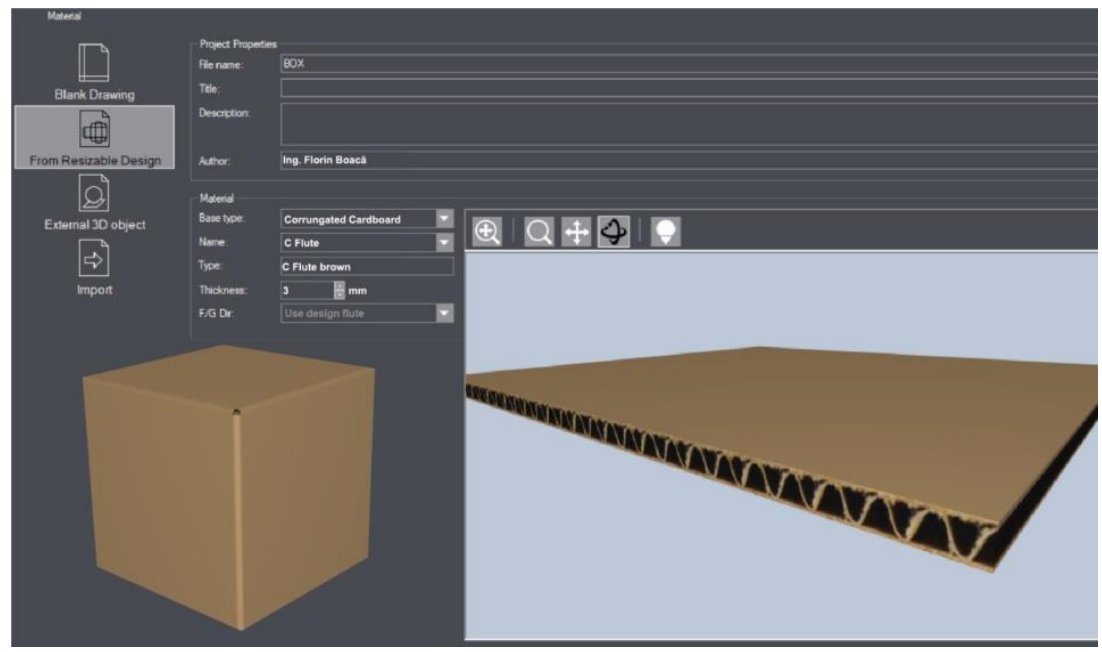

Figure 5. Package design

The method and the computing algorithm presented in the paer is based on test described in [13] The compression strength characteristic, named "box compression test" - BCT is obtained using the standards ISO 12048 and ASTM D642. In these standards the compression stiffness is calculated for different parts of the package, the top, the bottom and the middle section, having a harder stiffness compared to the top and bottom sections (liners).

The model was developed in years 1963 by McKee and al. [14]. The formula is:

$$
B C T=c E C T^{b}\left(\sqrt{D_{M C} D_{C D}}\right)^{(1-b)} Z^{(2 b-1)}
$$

where $b, c$ are empirical constants, used for panel rigidity respectively for the size. ECT is "edge compression test" value, $D_{M C}$ and $D_{M C}$ are the geometric mean of the bending stiffness in the machine direction and cross direction of principal material directions. Concerning the $E C T$ we can estimate a value of this test using the mathematical calculation relation proposed by Biancolini and Brutti [15]

$$
E C T_{t h}=R C T_{I_{-} l i n}+R C T_{O_{-} l i n}+R C T_{\text {flu }} \times C . O
$$

where $E C T$ theoretic is the sum of "ring compression test", $R C T$, for inner liner $\left(R C T_{\text {I-lin }}\right)$, outer liner, $\left(R C T_{O \text {-lin }}\right)$,respectively for the fluting (middle section), $\left(R C T_{f l u}\right)$. The C.O is the wave factor of the board. As we can see, the RCT is still used in characterizing the compressive strength of line board and fluting medium [16]. The characteristic of RCT mathematical computation is the combination between both compression and buckling of the material failure. For accomplish these hypotheses we use in this paper the relation adapted from Popil, 2010 [17]:

$$
R C T=C(S C T)^{b}\left(\sigma_{c r}\right)^{1-b}
$$

where $\sigma_{c r}$ is axial load of thin shell ring [26], SCT is the "short span compression test" value, $C$ and $b$ are empirical constants,. The relation for the buckling load is given by Timoshenko [18]

$$
\sigma_{c r}=\frac{E h}{R \sqrt{3\left(1-v^{2}\right)}}
$$

Where $E$ is modulus of elasticity, $v$ is the Poisson coefficient, $R$ is the radius of an equivalent fixed ring, $h$ is the thickness of the paperboard.

To find an estimated value for SCT factor we use the ISO 9895 but also TAPPI T826 standards. The SCT factor excludes the bending or buckling effects. Rennie (1995) [19] showed a correlation between SCT and RCT and propose an empirical model for mathematical calculus.

$$
S C T=R C T+0.005 \frac{T}{h^{2}}
$$


where $T$ is the bending stiffness and $h$ is the thickness of the paper. In this paper we will find the values of $S C T$ and $R C T$ using a system of the equations (3) and (5), knowing the material data and choosing the data of empirical constants from the previous standards.

In this paper we going to test a mechanical design for a box as is shown in Figure 5, with a perimeter of $700 \mathrm{~mm}$. Also, we consider a system of seven boxes superposed, each being of an equivalent load of $70 \mathrm{~N}$ (with charge). Also, the factor of safety is consider $\mathrm{S}=4$ [20]. In this way, the load for the box at the base of this seven boxes will be calculated as $\mathrm{F}=6 \times 70 \times 4=1680 \mathrm{~N}$.

By hypothesis we consider that the design model has the inner and outer liner made from the same paper material and geometric characteristic. The geometric characteristics are: the height for the liners is $h=0.184 \mathrm{~mm}$, for the flute, $h=3.66 \mathrm{~mm}$. The flute pitch is $7.95 \mathrm{~mm}$. The mass for the liners is $m=320$ $\mathrm{g} / \mathrm{m}$ and the mass for the flute is $m=250 \mathrm{~g} / \mathrm{m}$. The elasticity modulus for the liners is $E_{M D}=2149 \mathrm{MPas}$ (machine direction) and $E_{C D}=359 \mathrm{MPas}$ (cross direction). The elasticity modulus for the flute is $E_{M D}=2160 \mathrm{MPas}$ (machine direction) and $E_{C D}=456 \mathrm{MPas}$ (cross direction). The Poisson coefficient was considered the same for all components, $v=0.33$. We have calculate an equivalent modulus of elasticity for liners, as $E_{\text {eqv-lin }}=617 \mathrm{MPas}$, and an equivalent modulus for the flute, $E_{\text {eqv-f }}=753 \mathrm{MPas}$, After the mathematical calculus in relation (4) we solved the system of equations (3) and (5). With these results we have compute the $E C T_{\text {th }}$ from the relation (2). The wave factor was considered C. $\mathrm{O}=2.172$. The value for empirical constant $\mathrm{c}$ was taken equal to unit. The results, for various values of the empirical constant $b$ are shown in Figure 6.

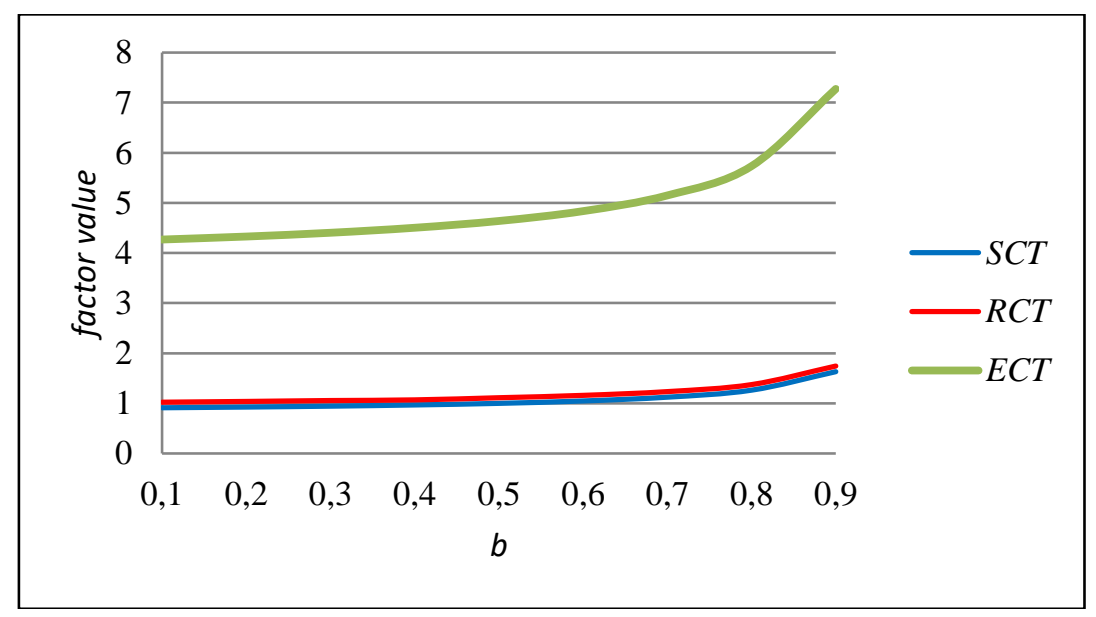

Figure 6. Results for $S C T, R C T$ and $E C T$ factors

As we can see, the values for these factors are have small variations for the constant $b$ values between 0.1 and 0.6. If we choose a value for $b=0.567$, the $E C T$ factor result is $E C T=4.762$. $Z$ is the perimeter, so $Z=0.7 \mathrm{~m}$. The result for $B C T$, computed with relation (1) is $B C T=1969 \mathrm{~N}$ which is greater than the maximum $F$ load. Our box package accomplish the demands of a good mechanical design.

\section{Conclusions}

We proposed an algorithm of computing the mechanical design for corrugated packaging box. The main conclusion is this mathematical calculus is based on a various experimental test (ones of them being introduced in several standards) but also is based on a various empirical constants. The values of these constants have to be chosen with great attention, due to a specific type of corrugated packaging box and the domain of use. 


\section{References}

[1] https://www.vci.de/vci/downloads-vci/chapter-6-corrugated-cardboard-packaging-statusoctober-2012.pdf, access, 09.09.2021.

[2] Twede, D., et al., Cartons, Crates and Corrugated Board, DEStech Pubication, 2015, 2-3.

[3] https://www.cabdirect.org/cabdirect/abstract/20183040660 .15.10.2021.

[4] Yan Zhou, Xiaocheng Zhang, Jinming Zhang, Yaohui Cheng, Jin Wu, Jian Wu, Jun Zhang, Molecular weight characterization of cellulose using ionic liquids, Polymer Testing, 93 2021, pg 1-6

[5] <https://cartonondulat.com/tipuri-de-carton.php, access pe 20.09.2020>

[6] <http://www.rossmann.ro/tipuri-de-carton-ondulat/, access pe 21.09.2020>

[7] Yi, Y., Wang, Z., Wennersten, R., Sun, Q., 2017. Life cycle assessment of delivery packages in China. Energy Procedia 105, 3711-3719.(http://refhub.elsevier.com/S0921-3449(19)300412/sbref0185)

[8] Bivainis, V., \&Jankauskas, V. (2015). Impact of corrugated paper board structure on puncture resistance. Materials Science. 21, 37-61

[9] Emblem, A., Emblem, H., Packaging technology, $1^{\text {st }}$ Edition, Fundamentals, Materials and Process, 2012., 31-32

[10] Harrysson, A., Ristinmaa, M. Largest rain elastoplastic model of paper and corrugated board International Journal of Solids and Structures, 45, 2008.

[11] Igges und Paperboard, Box compression strength, $<$ https://www.iggesund.com/services/knowledge/reference-manual/baseboard-physicalproperties/box-compression-strength/>., Access 01.10.2020.

[12] <https://inter-eng.umfst.ro/2009/files/proceedings/papers/paper54.pdf, access, 20.10.2021>

[13] Fadiji, T., Berry T.M., Coetzee, C.J., Opara U.L., Mechanical design and performance testing of corrugated paperboard packaging for the postharvest handling of horticultural produce, Biosystems Engineering, 171(2018), 220-244

[14] McKee, R.C., Gander,J.W., Wachuta, J., R., Compresion strength formula for corrugated boxes. Paperboard Packaging, 48(8), 149-159, 1963

[15] Biancolini, M.E., Brutti, C., Numerical and experimental investigation of the strength of corrugated board packages, Packaging Technology and Science, 16(2), 47, 60, 2003

[16] Dimitrov, K., Heindrich,M., Relationship between the edgewise compression strength of corrugated board and the compression strength of liner and fluting medium papers, Southern Forests, 71(3),227,233, 2009

[17] Popil, R.E., Hojjatie,B., Effects of component properties and orientation on corrugated container endurance. Packaging Technology and Science, 23(4), 189-202, 2010

[18] Timoshenko, S.P., Gere, J.M., Theory of Elastic Stability, McGraw Hill, New York

[19] Rennie, G.S., Quantifying the relationship between the short span compression and ring crush test, Tappi Journal, 78(7), 183-184

[20] Dan Gavrilescu, Cu Privire la Rezistenţa la Stivuire a Cutiilor din Carton Ondulat, Celuloză şi Hârtie, 62, nr1, 2013. 